\title{
Águas Duras - Uma Actividade Prática de Laboratório
}

\author{
Mário Valente ${ }^{1}$ e Helena Moreira
}

Neste artigo é sugerida uma actividade prática simples, integrada no programa de Física e Química A (nível 2), disciplina do $11^{\circ}$ ano. Nesta actividade propõe-se o estudo experimental da química do ião cálcio em fase aquosa, na presença de catiões carbonato ou hidrogenocarbonato. Este sistema está envolvido em processos como a formação de estalactites e estalagmites, a formação das conchas de moluscos e as consequências da chuva ácida sobre o calcário, entre outros. Realça-se que este trabalho prático pode ser efectuado com meios rudimentares em qualquer laboratório escolar.

\section{INTRODUÇÃO}

O estudo da dureza de uma água está preconizado no programa da disciplina de Física e Química A (nível 2) para o $11^{\circ}$ ano [1] de escolaridade, no ponto 2.4.1- A solubilidade e o controlo da mineralização das águas:

- Associar dureza total de uma água à presença predominante dos catiões cálcio e magnésio;

- Interpretar a origem da dureza de uma água em casos particulares: tipo dos solos e adição de compostos de cálcio nas Estações de Tratamento de Águas (ETAs);

- Perspectivar consequências da dureza de uma água a nível doméstico (alimentação, higiene, limpeza e electrodomésticos que utilizam essa água) e a nível industrial;

- Referir processos de uso doméstico de minimizar a dureza das águas (aditivos anti-calcário e resinas de troca iónica);

- Relacionar a dureza de uma água com a eficiência da lavagem com sabão; e

- Interpretar o efeito do dióxido de carbono na mineralização de uma água.

Entendemos a química, em particular nos seus níveis introdutórios, como uma ciência eminentemente experimental, pelo que se torna fundamental, sempre que possível, o recurso a actividades de laboratório. Este tema presta-se perfeitamente à realização de uma actividade prática, o que é reconhecido no programa, na figura da Actividade Laboratorial 2.6. (dure-

\footnotetext{
Colégio D. Duarte, Rua Visconde de Setúbal, 86 4200-497 Porto, Portugal
}

za da água e problemas de lavagem), que a nosso ver não é tão rica como poderia ser.

A presente sugestão de actividade prática contempla a verificação da formação de uma suspensão de carbonato de cálcio por acção do dióxido de carbono, a sua solubilização por acção de um excesso de dióxido de carbono, a sua re-precipitação por aquecimento, a verificação das consequências da presença de ião cálcio em solução na formação de espuma de sabão e a acção de agentes quelantes (EDTA).

\section{PARTE EXPERIMENTAL}

\section{Preparação de uma Solução Aquosa} Saturada de Hidróxido de Cálcio

O hidróxido de cálcio, $\mathrm{Ca}(\mathrm{HO})_{2}$, é um sólido branco ligeiramente solúvel em água. Para a preparação de uma solução de hidróxido de cálcio sugere-se a utilização de cal viva (óxido de cálcio) muito facilmente (e economicamente) encontrada em qualquer superfície comercial destinada a materiais de construção.

Esta solução deverá ser previamente preparada pelo professor, que usará, para um litro de água (da torneira, recém fervida), cerca de 5-10 g de cal viva, realizando a adição de forma cuidadosa pois a reacção entre o óxido de cálcio e a água é consideravelmente exotérmica. Após agitação da suspensão, o excesso de hidróxido de cálcio deve ser filtrado para o que se sugere a utilização de um funil grande com uma "bola de algodão" de dimensão adequada, isto é, que não possa deslizar pelo tubo do funil quando se iniciar a filtração.
A solução filtrada deve ser guardada em garrafas bem fechadas pois é muito sensível ao dióxido de carbono.

\section{EXPERIÊNCIA 1}

A ACÇÃO DO DIÓXIDO DE CARBONO SOBRE A SOLUÇÃO DE HIDRÓXIDO DE CÁLCIO

Enche-se um terço de tubo de ensaio com solução de hidróxido de cálcio recém preparada (Figura 1, tubo $A$ ). De seguida, com o auxílio de uma palhinha, borbulham-se lentamente várias expirações no seio da solução. Observa-se que esta rapidamente se torna turva (Figura 1, tubo B), com o aparecimento de um precipitado muito fino de carbonato de cálcio, o que é descrito pela seguinte equação:

$$
\begin{aligned}
& \mathrm{Ca}(\mathrm{HO})_{2}(\mathrm{aq})+\mathrm{CO}_{2}(\mathrm{aq}) \rightarrow \mathrm{CaCO}_{3}(\mathrm{~s})+ \\
& +\mathrm{H}_{2} \mathrm{O}(\mathrm{I})
\end{aligned}
$$

Neste ponto poderá ser interessante questionar os alunos sobre a proveniência do carbono que expiramos sob a forma de dióxido de carbono. De facto, a glicose $\left(\mathrm{C}_{6} \mathrm{H}_{12} \mathrm{O}_{6}\right)$ é o nosso "combustível", e é obtida dos alimentos que ingerimos. É da sua oxidação completa, a nível celular, que obtemos energia e o dióxido de carbono resultante não é mais do que o resíduo final, que acaba por ser expelido na expiração.

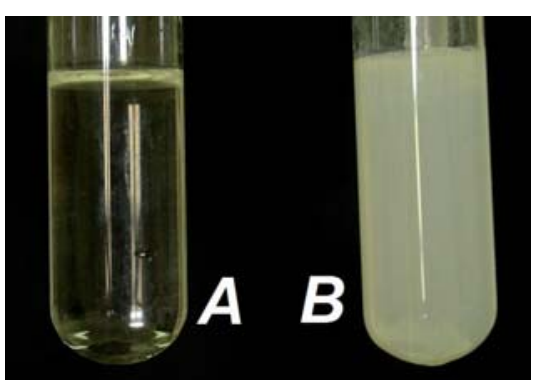

Figura 1 Tubos de ensaio contendo uma solução saturada de hidróxido de cálcio: $\mathbf{A}$ - antes e $\mathbf{B}$ - depois de se borbulharem sucessivas expirações 


\section{EXPERIÊNCIA 2:}

A ACÇÃO DE UM EXCESSO DE DIÓXIDO DE CARBONO SOBRE A SUSPENSÃO DE CARBONATO DE CÁLCIO

Prepara-se uma montagem que consiste num balão de kitasato no qual se colocam alguns pedaços de mármore ou calcário e um pouco de solução aquosa diluída (1:3) de ácido clorídrico, fechando rapidamente a boca do balão. À tubuladura lateral fixa-se um tubo de borracha que conduz a corrente de dióxido de carbono assim gerado para o interior do tubo de ensaio que contém a suspensão de carbonato de cálcio (Figura 1, tubo B).

O borbulhar de dióxido de carbono causa um deslocamento do equilíbrio descrito pela equação:

$$
\begin{aligned}
& \mathrm{CaCO}_{3}(\mathrm{~s})+\mathrm{CO}_{2}(\mathrm{aq}) \\
& \rightarrow \mathrm{Ca}\left(\mathrm{HCO}_{3}\right)_{2}(\mathrm{aq})
\end{aligned}
$$

no sentido directo (aplicação do princípio de Le Chatelier), verificando-se uma solubilização do carbonato de cálcio (Figura 2, tubo B). A solução resultante constitui um exemplo extremo de água dura.

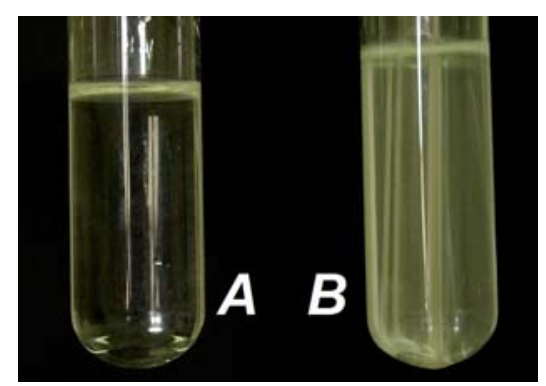

Figura 2 Tubos de ensaio contendo: A - uma solução saturada de hidróxido de cálcio e B depois de se borbulhar um excesso de dióxido de carbono

\section{EXPERIENCIA 3 :}

O EFEITO DO AUMENTO DE TEMPERATURA SOBRE UMA ÁGUA DURA

Passa-se um terço da solução de hidrogenocarbonato de cálcio acima preparada para um novo tubo de ensaio e aquece-se com o auxílio de uma lamparina de álcool. Verifica-se uma re-precipitação (Figura 3) de carbonato de cálcio, já que geralmente um aumento de temperatura causa uma diminuição da solubilidade da maioria dos gases em água (por exemplo, note-se que aparecem bolhinhas de ar na superficie interna de um recipiente onde se aquece água, pouco antes de esta entrar em ebulição). A remoção do dióxido de carbono faz com que o equilíbrio descrito pela equação 2 se desloque no sentido da formação de carbonato de cálcio, o que origina o precipitado.

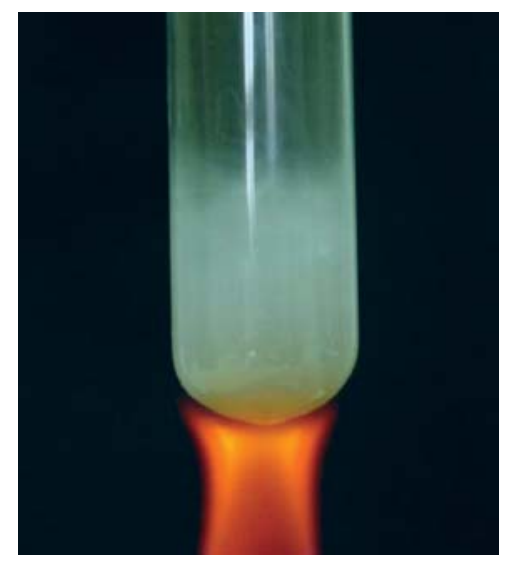

Figura 3 Aquecimento de uma solução saturada de hidrogenocarbonato de cálcio

Neste ponto devem salientar-se as consequências da utilização de águas duras em instalações industriais (como material de arrefecimento) ou em electrodomésticos como máquinas de lavar roupa (que possuem resistências de aquecimento): a deposição de carbonato de cálcio, de que resulta uma diminuição de rendimento de transferência de calor, o que pode causar danos no equipamento.

\section{EXPERIÊNCIA 4:}

A INFLUÊNCIA DA ÁGUA DURA NA ACÇÃO DO SABÃO

Passa-se um terço da solução de hidrogenocarbonato de cálcio acima preparada para outro tubo de ensaio e adicionam-se umas pequenas raspas de sabão em barra. Noutro tubo de ensaio contendo um volume aproximadamente igual de água da torneira também se adicionam algumas pequenas raspas de sabão em barra (não em excesso!).

Agitam-se vigorosamente as suspensões de sabão, de forma a provocar a formação de espuma. Verifica-se que o tubo de ensaio contendo água da torneira apresenta espuma (Figura 4, tubo A), mas o tubo de ensaio contendo água dura não apresenta espuma apreciável, mas sim um precipitado sobrenadante de sais de cálcio (Figura 4, tubo B).

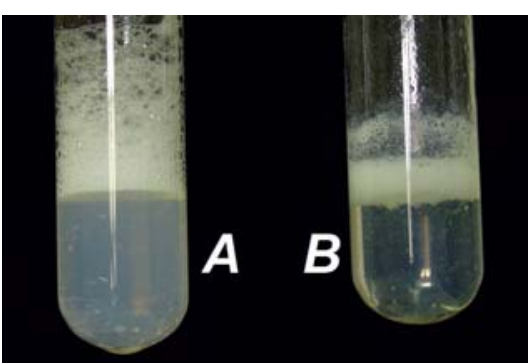

Figura 4 Suspensão de sabão: $\mathbf{A}$ - em água branda e B - em água dura, após agitação vigorosa

Numa proposta de investigação, pode sugerir-se que os alunos procurem uma razão para a formação do precipitado sobrenadante, a partir do conhecimento da estrutura e funcionamento do sabão tradicional e da presença de iões cálcio.

\section{EXPERIENNCIA 5:}

\section{A ACÇÃO DE AGENTES ANTI-CALCÁRIO}

Adicionam-se aproximadamente $0,5 \mathrm{~g}$ de EDTA sódico (sal de sódio do ácido etilenodiaminotetracético) - ou outro agente anticalcário - ao último terço da solução de hidrogenocarbonato de cálcio acima preparada. Juntam-se à solução resultante algumas raspas de sabão em barra e agita-se vigorosamente. Pode observar-se a formação de espuma como se a água não fosse dura (Figura 4, tubo A).

Neste ponto é de referir aos alunos que o EDTA - ou outro agente anti-calcário - "sequestra" os iões cálcio (e magnésio), diminuindo drasticamente a sua concentração em solução, o que impede que se forme o precipitado sobrenadante (Figura 4, tubo B).

\section{Conclusão}

Consideramos a actividade prática proposta útil, já que permite a visualização directa de todas as propriedades e consequências das águas duras que são mencionadas no programa da disciplina. A isso acresce que os reagentes envolvidos podem ser adquiridos com extrema facilidade e o equipamento usado é de uso corrente em qualquer laboratório escolar.

\section{REFERÊNCIA}

[1] Programa da disciplina de Física e Química A (nível 2) $11^{\circ}$ ou $12^{\circ}$ anos: http://www.dgidc.min-edu.pt/programs/ prog_eg.asp 


\section{Actualidade Científica}

\section{Electricidade sem Carbono}

A revista Nature (em News Feature) do dia 14 de Agosto apresenta uma análise às potencialidades de desenvolvimento de fontes de electricidade com carbono zero, para responder às crescentes preocupações com o efeito de estufa, as alterações climáticas e a crescente procura de energia.

Segundo o estudo aí apresentado, produzem-se anualmente 18.000 terawatts-hora (TWh) (18.000 biliões ou $18 \times 10^{15}$ watts-hora) de energia eléctrica por ano, correspondendo a cerca de $40 \%$ das necessidades mundiais totais de energia.

Esta energia eléctrica corresponde a uma potência média de 2,05 terawatts (TW). Como o consumo de energia não é constante ao longo do dia, a potência instalada é, por isso, bastante superior.

Para produzir o valor de energia eléctrica mencionado são produzidas por ano mais de 10 gigatoneladas (ou 10 mil milhões de toneladas) de dióxido de carbono.

Para reduzir estas emissões, pode-se, por um lado, aumentar a eficiência de produção de energia (opção com ganhos limitados, havendo ainda o paradoxo de um aumento da eficiência de produção ser certamente acompanhado de um aumento do consumo) ou, por outro lado, na opção que globalmente permitirá combater as alterações climáticas, aumentar a contribuição das fontes de electricidade que não geram carbono - fontes de electricidade com carbono zero.

No referido estudo são analisados a contribuição actual e o potencial de expansão das fontes com carbono zero disponíveis (hidroeléctrica, fissão nuclear, biomassa, eólica, geotérmica, solar e oceânica). A fusão nuclear, que poderia satisfazer as necessidades energéticas da Terra, encontra-se ainda numa fase de desenvolvimento, não sendo de esperar que haja reactores comerciais antes de 2040. Uma outra opção, que consiste na colocação em órbita de satélites com painéis solares capazes de absorver a energia solar ininterruptamente, re-enviando-a para a Terra sob a forma de micro-ondas, requer o transporte para órbita de milhares de toneladas de células solares. Contudo, o preço das viagens espaciais é ainda demasiado elevado, pelo que esta opção não deve estar disponível a médio prazo.

Capacidade - A potência máxima que poderia ser gerada se todos os recursos hídricos fossem explorados é superior a 10 TW. Contudo, a eficiência de exploração deste potencial pode não exceder os 30\%. A Europa é quem faz um uso mais eficiente desta fonte, estando a África no outro extremo. A Ásia possui já a maior capacidade instalada, possuindo também o maior potencial de crescimento.

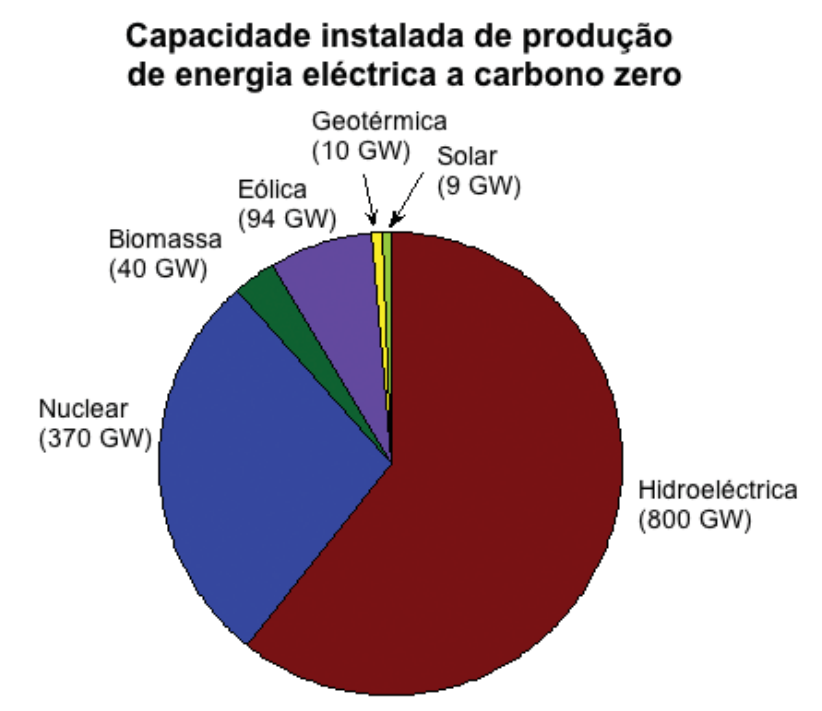

\section{Hidroeléctrica}

As barragens hidroeléctricas em funcionamento têm uma capacidade instalada de 800 gigawatts (GW) e fornecem quase um quinto do consumo mundial de electricidade. Uma das razões para o enorme peso desta fonte de electricidade resulta do facto de se tratar de um recurso largamente disperso por todo o globo, sendo, nalguns países, a principal fonte de energia eléctrica.

Custos - Segundo a Associação Internacional de Hidroenergia (International Hydropower Association, IHA), os custos de uma instalação variam com a dimensão e localização, com um valor médio de cerca de 2 milhões de euros por megawatt de capacidade instalada. Os custos de operação são baixos, sendo os custos de produção de electricidade de $0,02 €$ a $0,07 €$ por $\mathrm{kWh}$, o que torna as barragens competitivas com o carvão e o gás.
O caso da China, em que a barragem das Três Gargantas tem uma capacidade de $18 \mathrm{GW}$ e tem em desenvolvimento uma capacidade adicional de $120 \mathrm{GW}$, é o mais conhecido. Segundo a IHA, a capacidade instalada pode triplicar se houver investimento suficiente.

Vantagens - A produção de electricidade por esta via evita a utilização de carvão, bem como os custos de exploração e de transporte de carvão. Possui a enorme versatilidade de poder responder às variações da procura, podendo ser usada como fonte de apoio a outras fontes renováveis de menor fiabilidade. Por isso, as barragens fornecem, em média, cerca de metade da potência da sua capacidade instalada.

Desvantagens - Os recursos hídricos não estão igualmente distribuídos pelas várias regiões do globo. Por vezes, com aconteceu na China e Índia, a construção de barragens implica a 
movimentação de elevado número de pessoas. As barragens constituem barreiras para a movimentação de sedimentos e de peixes. Apesar de a produção de hidroelectricidade ser feita a carbono zero, a decomposição da biomassa acumulada nas albufeiras, com a libertação de dióxido de carbono e metano, pode ter um efeito idêntico à queima de combustíveis fósseis. Uma vez que esta tecnologia é já uma tecnologia "madura", há pouca margem de melhoria de eficiência de produção.

Conclusão - Trata-se de uma tecnologia barata e estabelecida, com custos ambientais elevados. Poderá aumentar-se a capacidade instalada em cerca de um TW.

\section{Fissão Nuclear}

Apesar de o acidente ocorrido na central nuclear de Chernobyl em 1986 (e de outro acidente anterior em Three Mile Island, na Pensilvânia (EUA)) ter relançado as dúvidas sobre a sua segurança, volta a estar na ordem do dia a utilização de energia nuclear. Em 2007, havia 35 centrais nucleares em construção, quase todas na Ásia. Os 439 reactores em operação correspondem a uma capacidade instalada de $370 \mathrm{GW}$, contribuindo com cerca de $15 \%$ para a produção global de electricidade.

Custos-Os custos de produção variam de cerca de $0,018 €$ a $0,050 €$ por kWh.

Capacidade - A produção de energia está limitada pelo stock de combustível. Os reactores actuais funcionam com urânio, estimando-se as reservas em cerca de 5,5 milhões de toneladas, o que garante o fornecimento para cerca de 80 anos, considerando o consumo actual de 66.500 toneladas por ano e se não forem descobertas novas jazidas. Com as possibilidades de se usar outro elemento (tório, Th) como combustível (com a necessária modificação dos reactores) e a modificação dos reactores actuais, as necessidades poderiam ser inteiramente satisfeitas por esta fonte.

Vantagens - Os custos do combustível são relativamente baixos, e os reactores podem funcionar à capaci- dade total quase constantemente (nos EUA fornecem cerca de $90 \%$ da capacidade instalada).

Desvantagens - Não há uma solução consensual sobre a forma de armazenar os resíduos gerados durante os últimos 50 anos, o que dificulta a aceitação pelo público de novas construções. Por outro lado, é difícil separar a disseminação destas fontes de electricidade do problema da proliferação de armas nucleares. A possiblidade de se utilizar esta fonte a longo prazo requer a aceitação pública da tecnologia actual e de nova tecnologia. Dados os elevados custos de construção, os baixos custos de produção resultam do longo tempo de vida das centrais nucleares. Esta seria uma opção cara a curto prazo.

Conclusão - É possível que se atinja uma capacidade instalada da ordem dos TW nas próximas décadas, mas, politicamente, pode ser difícil de sustentar esta evolução.

\section{Biomassa}

Madeira, resíduos de colheitas agrícolas e outras fontes biológicas são usados como fonte de electricidade. A capacidade de produção foi estimada em 2005 em cerca de $40 \mathrm{GW}$, maior do que qualquer outra fonte de energia renovável, com excepção das fontes de electricidade eólica e hidroeléctrica. A biomassa é ainda usada como complemento do carvão e do gás nalgumas instalações de produção de electricidade.

Custo - Os custos de produção são da ordem de $0,02 €$ a $0,04 €$ por kWh, quando a biomassa é queimada em conjunto com carvão, aumentando para $0,03 €$ a $0,06 €$ por $\mathrm{kWh}$ em instalações especificamente construídas para queimar biomassa. Para minimizar os custos de produção, é importante garantir uma fonte de biomassa fiável e próxima (para reduzir os custos do transporte).

Capacidade - A biomassa é limitada pela área de terreno disponível, eficiência da fotossíntese e disponibilidade de água. A OCDE estimou, em 2007, que haverá cerca de quinhentos milhões de hectares de terrenos não utilizados na agricultura que poderiam ser usados para a produção de biomassa sustentada pela chuva. Prevê-se que, em 2050, se poderá atingir um aumento na produção de electricidade de 3 a 5 TW. O armazenamento da energia solar sob a forma de energia de ligação química dá à biomassa a vantagem de ser a fonte ideal, entre todas as renováveis, de combustível para transportes. Contudo, a transformação de biomassa em combustível é menos eficiente do que a sua queima para produzir electricidade.

Vantagens - As plantas são, por natureza, neutras do ponto de vista do balanço do carbono e renováveis. As tecnologias de queima são eficientes e bem estabelecidas. Se for queimada em instalações equipadas para reter e armazenar carbono, pode tornar-se na única tecnologia negativa em termos de carbono, podendo, por isso, promover a redução da quantidade de dióxido de carbono na atmosfera.

Desvantagens - Muito do terreno disponível vai ser necessário para produzir alimento que satisfaça as necessidades de uma população crescente. É, por isso, provável que haja uma oposição crescente à utilização de terrenos para produzir biomassa para a produção de energia. A utilização de biomassa para a produção de electricidade, por retirar carbono que iria enriquecer os terrenos, pode não ser, a longo termo, sustentável.

Conclusão - Se o aumento das culturas para a produção de energia se tornar aceitável e sustentável, parte delas pode vir a ser usada na produção de electricidade. A possibilidade de conseguir unidades com balanço de carbono negativo é uma capacidade única e atractiva.

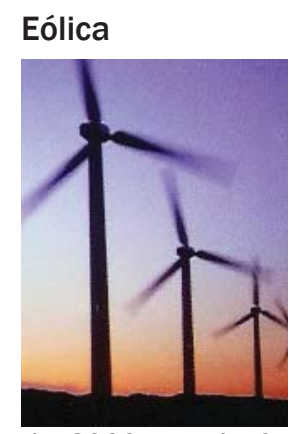

A energia eólica tem sofrido uma expansão muito para além do expectável há alguns anos. A capacidade instalada estimada em Janeiro de 2008 era de 94 GW. Nos últimos cinco anos sofreu um aumento anual 
de $25 \%$. Se nos próximos seis anos aumentar a uma média de $21 \%$, no final deste período a capacidade terá duplicado. Apesar desta perspectiva, a sua contribuição, em termos globais, tem sido pequena. As instalações têm produzido apenas cerca de $20 \%$ da sua capacidade total.

Também Portugal tem promovido significativamente esta alternativa para aumentar a contribuição das fontes de energia renováveis.

Custos - O custo das instalações quase duplica quando, em vez de serem feitas em terra, elas são construídas no mar. O custo de produção é de 0,04€ a $0,06 €$ por kWh, o que a torna competitiva, no limiar inferior, com o custo de produção a partir do carvão. Como num grande número de países as instalações beneficiam de subsídios, os custos descem abaixo dos custos de produção a partir do carvão, o que resultou na enorme expansão destas instalações. A evolução mais significativa na redução dos custos de produção tem sido conseguida através do desenvolvimeno tecnológico, em particular das turbinas, através do aumento de eficiência e redução de preço.

Capacidade - Estima-se em centenas de TW a quantidade de energia produzida pelo movimento da atmosfera da Terra. Em 2005, dois investigadores da Universidade de Stanford (EUA) estimaram que seria possível produzir 72 TW de electricidade usando 2,5 milhões de turbinas actuais, colocadas em $13 \%$ dos locais nos quais a velocidade do vento é de pelo menos $25 \mathrm{~km} / \mathrm{h}$.

Vantagens - A maior vantagem da produção eólica é que, tal como a hidroeléctrica, não necessita de combustível. Os únicos custos são os da construção e manutenção das instalações e das redes de distribuição. 0 desenvolvimento tecnológico pode reduzir custos de instalação e aumentar a sua sustentabilidade.

Desvantagens - A intermitência do vento é a grande limitação desta forma de produção eléctrica. Podem facilmente satisfazer-se $20 \%$ das necessidades de uma rede de distribuição, mas para conseguir ultrapassar este valor, é necessário ultrapassar ou limitar o efeito da variabilidade do vento. Por outro lado, a energia do vento é de muito baixa densidade, o que se traduz em grandes áreas de ocupação. A Alemanha cobriu a maior parte das suas terras mais ventosas com turbinas, conseguindo uma capacidade instalada de $22 \mathrm{GW}$. Contudo, apenas satisfaz $7 \%$ da suas necessidades de electricidade.

Conclusão - Com grande ocupação de várias regiões do globo e com uma redução dos custos de acesso às instalações no mar, poderá atingir-se uma capacidade de 1 TW ou mais.

\section{Geotérmica}

O interior da Terra contém enormes quantidades de calor: algum permanece desde a sua formação, outro foi gerado pelo decaimento de elementos radioactivos.

Como a condutividade térmica das rochas é baixa, o fluxo de calor para a superfície é muito lento; se fosse mais rápido, o centro da Terra teria congelado e os seus continentes teriam parado de se movimentar há muito tempo. Apenas em alguns locais (fontes geotérmicas) este fluxo de calor até à superfície é significativo. E, nestes, têm sido construídas centrais para converter esse calor em electricidade. Entre a dúzia de países onde esta produção é possível, em apenas cinco - Costa Rica, El Salvador, Islândia, Quénia e Filipinas - a electricidade produzida por esta forma excede $15 \%$ da produção total. A capacidade total instalada é de cerca de $10 \mathrm{GW}$, tendo crescido cerca de $3 \%$ ao ano.

Custos - Os custos foram estimados em $0,04 €$ por kWh para os melhores locais. A situação é idêntica à exploração dos recursos minerais, em termos da natureza dos terrenos, e temperaturas das fontes geotérmicas.

Capacidade absoluta - A Terra perde 40 a 50 TWano de calor, o que corresponde a um pouco menos de 0,1 W por metro quadrado. Em termos de comparação, a energia solar atinge a Terra com uma média de $200 \mathrm{~W}$ por metro quadrado. Com a tecnologia actual, estima-se que se possam ex- plorar $60 \mathrm{GW}$ do fluxo de calor. Com uma tecnologia mais avançada, antecipa-se que se possa atingir cerca de $1 \mathrm{TW}$, o que tornaria esta fonte tão produtora de electricidade quanto as barragens, actualmente.

Vantagens - As centrais geotérmicas não requerem combustível e têm uma fonte de energia regular. $\mathrm{O}$ calor restante depois da produção de electricidade pode ser usado para aquecimento doméstico ou em processos industriais. A pesquisa e perfuração de fontes geotérmicas previamente não exploradas tornou-se mais fácil com tecnologia de mapeamento e com tecnologia de perfuração desenvolvidas pela indústria do petróleo.

Desvantagens - Fontes de elevada qualidade são raras. Pode haver fuga de dióxido de carbono a partir de alguns campos geotérmicos e pode haver contaminação - a água que transporta o calor até à superfície pode transportar compostos que não deveriam ser libertados em aquíferos. Em regiões secas, a disponibilidade de água pode constituir um constrangimento. A exploração em larga escala requer tecnologia que, embora plausível, não foi ainda demonstrada.

Conclusão - A capacidade poderá ser aumentada em mais de uma ordem de grandeza. Na ausência de melhorias espectaculares, é pouco provável que ultrapasse a produção hidroeléctrica e eólica e que atinja 1 TW.

\section{Solar}

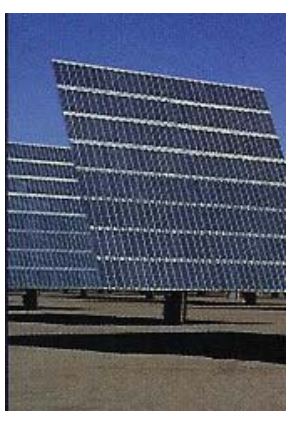

As plantas, através da fotossíntese,conseguem converter até cerca de $1 \%$ da energia solar que atinge a sua superfície. Um painel fotovoltaico comercial pode converter cerca de $12 \%$ a $18 \%$ da energia solar em energia eléctrica, havendo módulos com eficiências de conversão de $20 \%$. A capacidade solar instalada está estimada em cerca de 9 GW. A energia eléctrica efectivamente produzida estima-se em cerca de $14 \%$ (factor de capacidade) deste 
valor, dado que as noites e as nuvens diminuem a potência disponível. De todas as fontes de energia renováveis é a que tem um factor de capacidade mais baixo.

Além das células fotovoltaicas, também a energia térmica solar pode, após concentração, ser usada para aquecer fluidos que movimentam turbinas produtoras de electricidade.

Custos - Contabilizando os custos de fabrico das células fotovoltaicas e de instalação, os custos de produção de electricidade, durante o tempo de vida de uma instalação, são da ordem de $0,18 €$ a $0,29 €$ por kWh. Contudo, os custos de fabrico estão a decrescer e prevê-se que os custos de instalação também diminuam com a integração das células fotovoltaicas nos materiais de construção em vez da utilização de painéis suspensos para aplicações domésticas.

Capacidade - A superfície da Terra recebe cerca de 100.000 TW de potência solar. A energia recebida durante uma hora chegaria para satisfazer as necessidades de energia da humanidade durante um ano. Há regiões desertas do globo onde uma linha de células fotovoltaicas actuais com 7 ou $8 \mathrm{~km}$ de comprimento poderia gerar $1 \mathrm{GW}$ de electricidade. Teoricamente, as necessidades mundiais de energia primária poderiam ser satisfeitas com uma área de células solares inferior a um décimo da área do deserto do Saara. Há também uma estimativa segundo a qual a utilização de painéis solares em todos os telhados das residências e edifícios comerciais dos EUA poderia produzir uma quantidade anual de electricidade igual à usada no país em 2004. Em climas mais temperados, as perspectivas não são tão promissoras.

Vantagens - O Sol representa uma fonte de energia ilimitada, sem custos, que é largamente distribuída e não deixa resíduos. A tecnologia solar é bem aceite pelo público. Esta tecnologia é muito adequada à produção de energia fora das redes de distribuição e em áreas sem infraestruturas bem desenvolvidas. Quer a tecnologia fotovoltaica quer a tecnologia térmica solar concentrada possuem elevada margem de crescimento.
Desvantagens - A escuridão é a derradeira limitação. As células fotovoltaicas não geram electricidade durante a noite e em lugares com cobertura por nuvens frequente e intensa. A produção de electricidade flutua de forma imprevisível durante o dia. Alguns sistemas térmicos solares concentrados contornam esta limitação armazenando calor durante o dia, sendo este usado durante a noite (sais fundidos constituem um meio de armazenamento). Esta é uma das razões pelas quais estes sistemas são preferíveis aos sistemas fotovoltaicos para grandes instalações. Outro problema resulta de as grandes instalações serem construídas em desertos, pelo que a distribuição de electricidade pode criar problemas.

Uma possível desvantagem de alguns sistemas fotovoltaicos mais avançados é a utilização de elementos raros que podem estar sujeitos a aumentos de preço e restrições de fornecimento.

Conclusão - A médio e longo termo, considerando também os possíveis desenvolvimentos tecnológicos, a energia solar parece ser a tecnologia sem carbono mais promissora. Contudo, sem um significativo desenvolvimento das opções de armazenamento, não pode resolver o problema na globalidade.

\section{Oceânica}

Os oceanos oferecem duas fontes de energia cinética: a das marés e a das ondas. Nenhuma delas representa, actualmente, uma contribuição significativa para a produção mundial de electricidade, contudo, esta situação não tem desmotivado os entusiastas do desenvolvimento de esquemas para o seu aproveitamento.

A maior instalação de produção de energia a partir das marés, no Reino Unido, com uma capacidade de 240 MW está em uso desde há quarenta anos. Uma outra unidade, com uma tecnologia diferente, foi instalada este Verão na Irlanda do Norte, com uma turbina de 1,2 MW.

A maioria das tecnologias para capturar a energia das ondas tem permanecido em fase de teste. Este ano foram instaladas na costa de Portugal, próximo da Póvoa de Varzim, três máquinas que, combinadas, possuem uma capacidade de 2,25 MW.

Custos - Para a produção de electricidade a partir da energia das marés, os custos estão estimados em $0,14 €$ a $0,28 €$ por $\mathrm{kWh}$, sendo de $0,65 €$ por kWh para os sistemas com base na utilização da energia das ondas. Ambas as tecnologias se encontram muito longe da produção em larga escala, necessária para reduzir significativamente os custos.

Capacidade - A interacção da massa da Terra com os campos gravíticos da Lua e do Sol produz uma energia de marés estimada em 3 TW. Só uma pequena fracção está realisticamente disponível para a produção de energia eléctrica.

A potência das ondas oceânicas está estimada em mais de 100 TW, estimando-se que apenas 1 a 10 TW estejam acessíveis. Contudo, mesmo com um desenvolvimento muito significativo, não se antevê que a potência das ondas se possa aproximar da capacidade hidroeléctrica actualmente instalada.

Vantagens - As marés são previsíveis e, em alguns locais, as barragens podem oferecer o potencial de produzir electricidade em larga escala, que seria significativa em termos regionais. As ondas não são tão constantes, mas são mais fiáveis do que os ventos.

Desvantagens - Ondas e marés são muito variáveis, geograficamente. A construção de turbinas que resistam no mar durante décadas em condições violentas é difícil. As ondas e marés tendem a ser encontradas longe das redes de distribuição eléctrica, pelo que o transporte da energia gerada coloca problemas adicionais.

Conclusão - A contribuição é insignificante à escala global.

(Adaptado do relatório publicado por Quirin Schiermeier, Jeff Tollefson, Tony Scully, Alexandra Witze e Oliver Morton em News Feature, Nature de 14 de Agosto, vol. 454) 


\section{Actualidade Científica}

\section{Prémio Nobel da Físıca 2008}

A Academia de Ciências Real Sueca decidiu, no passado dia 7 de Outubro, atribuir o Prémio Nobel da Física de 2008 a um trio de cientistas de origem japonesa pelo seu trabalho sobre a quebra de simetrias fundamentais da natureza.

Este prémio foi repartido entre Yoichiro Nambu, nascido em 1921 em Tóquio, Professor Jubilado no Instituto Enrico Fermi na Universidade de Chicago, pelo seu trabalho sobre a descoberta dos mecanismos da quebra espontânea de simetria na física subatómica; e a dupla constituída por Makoto Kobayashi, que nasceu em 1944 in Nagoya, e é Professor Jubilado na organização de Pesquisa do Acelerador de Altas Energias (High Energy Accelerator Research Organization (KEK)) em Tsukuba e por Toshihide Maskawa, nascido em 1940, Professor Jubilado no Instituto de Física Teórica de Yukawa, na Universidade de Quioto, pela descoberta da origem da quebra de simetria que prevê a existência de pelo menos três famílias de quarks na natureza.

São os desvios de simetria ao nível miscroscópico que explicam que o nosso mundo são se comporte de forma exactamente simétrica.

Nos anos de 1960, Yoichiro Nambu formulou a sua descrição matemática de quebra espontânea de simetria na física das partículas elementares. As teorias de Nambu estão presentes no Modelo Standard da física das partículas elementares.

As quebras de simetria estudadas por Nambu são diferentes das descritas por Makoto Kobayashi e Toshihide Maskawa. Estas parecem ter existido na natureza desde o início do universo. Apesar de se terem inicialmente manifestado em experiências de partículas em 1960, só recentemente as explicações de Kobayashi e Maskawa foram confirmadas. Em 2001, dois detectores de partículas (nos EUA e no Japão) detectaram, independente- mente, as quebras de simetrias previstas por Kobayashi e Maskawa quase três décadas antes.

Uma quebra de simetria do mesmo tipo ainda não explicada está na génese do universo no Big Bang. Se tivessem sido criadas quantidades iguais de matéria e de anti-matéria, deveriam ter-se aniquilado. Contudo, um pequeno desvio de uma partícula a mais de matéria por cada 10 mil milhões de partículas de anti-matéria, permitiu que o nosso universo sobrevivesse. Permanece sem resposta a forma como tal ocorreu. Talvez o novo acelerador de partículas LHC no CERN possa vir a revelar alguns dos mistérios que continuam a desafiar-nos. (Adaptado do "Press Release" de nobelprize.org)

\section{Prémio Nobel da Químıca 2008}

O Prémio Nobel da Química de 2008 foi repartido entre Osamu Shimomura (do Laboratório de Biologia Marítima e da Boston University Medical School, EUA), Martin Chalfie (da Universidade de Columbia, Nova lorque) e Roger Y. Tsien (da Universidade da Califórnia, San Diego) pela descoberta e desenvolvimento da proteína fluorescente verde (GFP).

A GFP foi inicialmente observada numa alforreca em 1962, tendo-se tornado numa das ferramentas mais importantes em biociência contemporânea. Com a ajuda desta proteína, usando-a como marcador fluorescente, os investigadores podem seguir movimentos, posições e interacções de proteínas marcadas. Tal pemitiu observar processos até então invisíveis, tais como o desenvolvimento de células nervosas no cérebro ou a propagação de células cancerígenas.

Osamu Shimomura (nascido em Quioto em 1928) isolou pela primeira vez a GFP de alforrecas Aequorea victoria, que se encontram nas correntes da costa oeste da América do Norte. Descobriu que esta proteína exibia uma forte fluorescência verde quando exposta a luz ultra-violeta.

Martin Chalfie (nascido em 1947) demonstrou a importância da GFP como marcador genético luminoso em vários processos biológicos.

Roger Y. Tsien (nascido em Nova lorque em 1952) contribuiu para a compreensão do mecanismo de fluorescência da GFP. Além disso, expandiu as cores para além do verde de forma a obter proteínas e células com várias cores, o que permite o seguimento simultâneo de vários processos biológicos. (Adaptado do "Press Release" de nobelprize.org)

JM

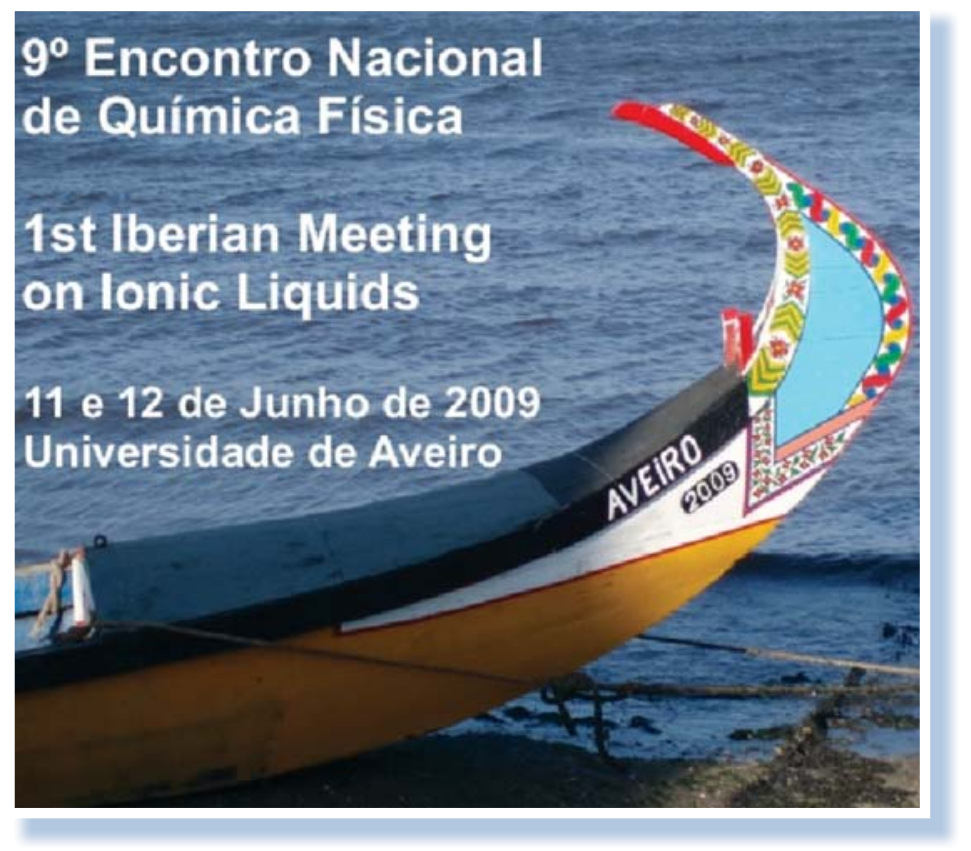




\section{Communicating Chemistry}

"Communications are an important complement to the Full Papers in Chemistry A European Journal. This change makes the journal even more attractive to younger

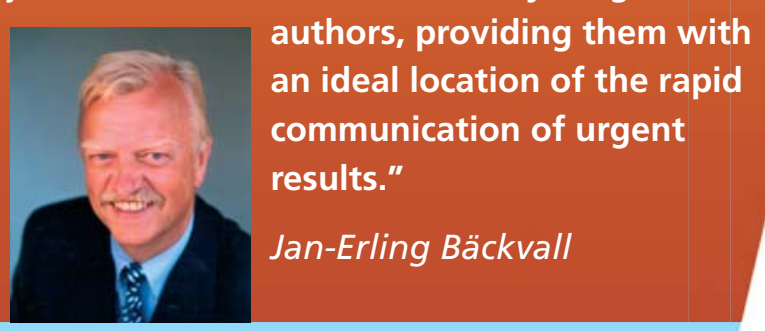

\section{Good reasons to publish in} Chemistry - A European Journal

New in 2008: Communications and Reviews

Top quality contributions covering all areas of chemistry and related fields

A truly international journal - Submissions from about 50 different countries

Over 10000 pages of top quality chemistry

Geographical Distribution of Published Articles in 2007

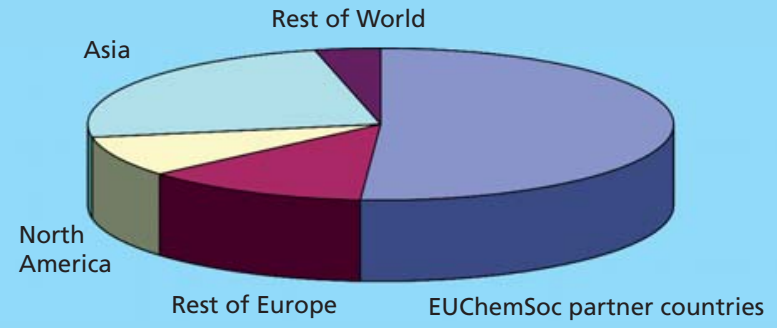

Submit your next excellent manuscript to Chemistry - A European Journal through manuscript press

\section{CHE JUIETRI} A EUROPEAN JOURNAL

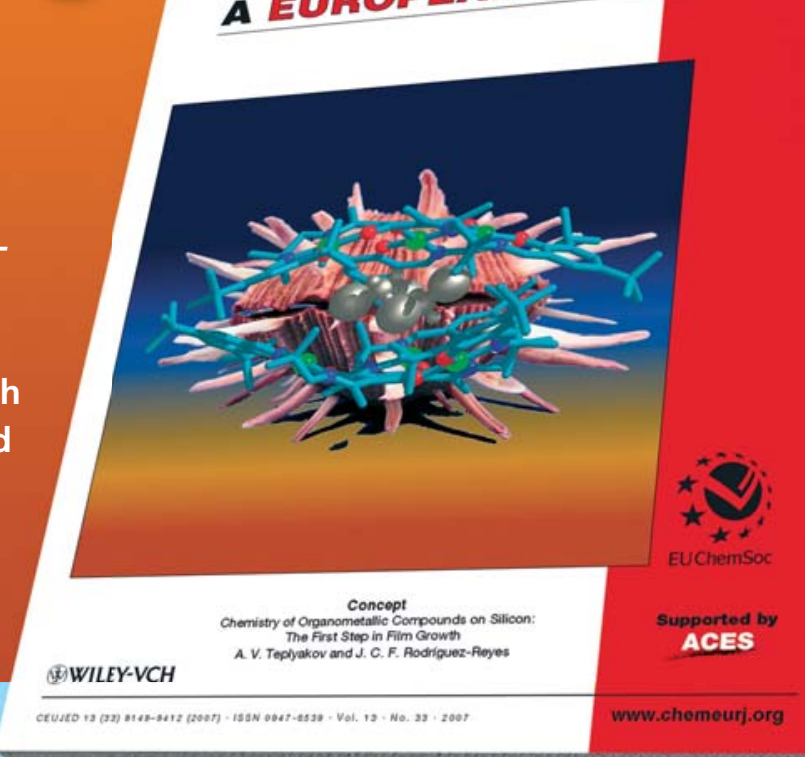

ISSN: 0947-6539 (print), 1521-3765 (online) 2008. Volume 14. 36 Issues

High ISI Impact Factor: 5.015 (2006

Submitted Papers According to Origin of Submission 200;

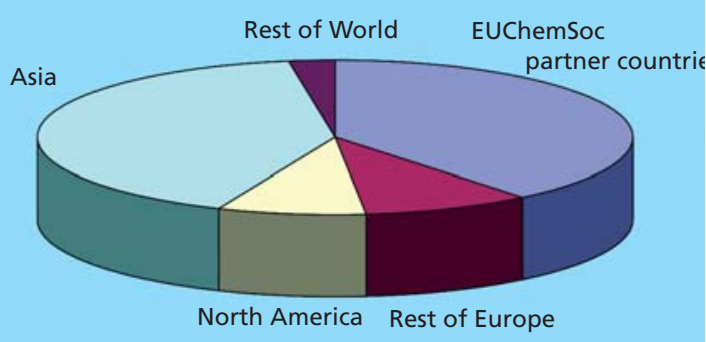

Chemistry - A European Journal is owned and supported by 14 European chemical societies and supported by

\section{Customer Service:}

cs-journals@wiley.com (North and South America) service@wiley-vch.de (Germany/Austria/Switzerland) cs-journals@wiley.co.uk (all other areas)

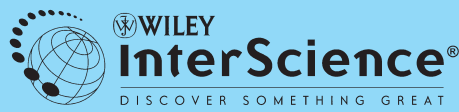

